\title{
Low HDL Cholesterol, Smoking and IL-13 R130Q Polymorphism are Associated with Myocardial Infarction in Greek Cypriot Males. A Pilot Study
}

\author{
Stavroulla Xenophontos ${ }^{1}$, Marilena Hadjivassiliou ${ }^{1}$, Alexandros Karagrigoriou ${ }^{2}$, \\ Nafsika Demetriou ${ }^{1}$, George Miltiadous ${ }^{3}$, Ioannis Marcou ${ }^{4}$, Moses Elisaf ${ }^{3}$, \\ Dimitri P. Mikhailidis ${ }^{5}$ and Marios A. Cariolou* ${ }^{*}, 1$
}

\begin{abstract}
${ }^{I}$ Department of Cardiovascular Genetics \& The Laboratory of Forensic Genetics, The Cyprus Institute of Neurology and Genetics, Nicosia, Cyprus, ${ }^{2}$ Mathematics and Statistics Department, University of Cyprus, Nicosia, Cyprus, ${ }^{3}$ Department of Internal Medicine, Medical School, University of Ioannina, Ioannina, Greece, ${ }^{4}$ Department of Internal Medicine, Nicosia General Hospital, Nicosia, Cyprus and ${ }^{5}$ Department of Clinical Biochemistry, Royal Free Hospital Campus, University College London, Pond Street, London, NW3 2 QG, UK
\end{abstract}

\begin{abstract}
This study was carried out in Greek Cypriot males to identify risk factors that predispose to myocardial infarction (MI). Genetic and lipid risk factors were investigated for the first time in a Greek Cypriot male case-control study. Contrary to other studies, mean low density lipoprotein cholesterol did not differ between cases and controls. High density lipoprotein cholesterol on the other hand, although within normal range in cases and controls, was significantly higher in the control population. In agreement with many other studies, smoking was significantly more prevalent in cases compared with controls. In pooled cases and controls, smokers had a significantly lower HDL-C level compared with nonsmokers. The frequency of the IL-13 R130Q homozygotes for the mutation (QQ), as well as the mutant allele were significantly higher in cases compared with controls. The IL-13 R130Q variant, or another locus, linked to it, may increase the risk of MI.
\end{abstract}

Key Words: Smoking, myocardial infarction, cholesterol, Cyprus.

\section{INTRODUCTION}

Identified modifiable cardiovascular disease (CVD) risk factors include dyslipidaemia, hypertension, diabetes, smoking, obesity and metabolic syndrome [1-6]. Dyslipidaemia is a major risk factor for CVD and improving lipid levels with statins is an effective regimen [7-11]. Many genetic risk factors have also been identified which are pro-thrombotic, proinflammatory or pro-atherogenic $[12,13]$. It is also important to consider gene-gene interactions and gene-environment interactions since the combination of risk factors may increase the severity of CVD and the risk of morbidity and mortality [14]. In the present study, a battery of functional gene polymorphisms that have been reported to increase the risk for myocardial infarction (MI) was selected for investigation. The following genetic variables were tested: IL6174G/C, IL13 R130Q, Stromelysin 5A/6A, ACE D/I, ApoE, GPIIIa A1/A2, MTHFR C677T, ECNOS G894T, Factor V G1691A, Factor II G20210A, PAI-1 4G/5G and PON1 L55M. Cases $(n=77)$ and controls $(n=79)$ were unrelated individuals, age $30-65$ years.

Two of the most intensively studied candidate gene polymorphisms are the ACE D/I and Apo E gene polymorphisms. The former plays a role in blood pressure (BP) regulation while the latter influences lipid metabolism. Several

*Address correspondence to this author at the Department of Cardiovascular Genetics \& The Laboratory of Forensic Genetics, The Cyprus Institute of Neurology and Genetics, 6 Airport Avenue, 1683 Nicosia, Cyprus; Tel: 0035722392651; Fax: 0035722392638; E-mail: cariolou@ cing.ac.cy studies found an association between the deletion allele of the ACE gene and the E4 allele of the ApoE gene and CVD $[15,16]$. In contrast, case-control studies in the Greek population do not support the latter association of CVD with the Apo E4 allele and further, a protective role was reported for the E3/4 genotype, as well as the E2 allele [17-19]. The paraoxonase 1 (PON1) L55M gene polymorphism was investigated because this is an integral enzyme of the high density lipoprotein cholesterol (HDL-C) molecule that can protect low density lipoprotein cholesterol (LDL-C) from oxidative modification and subsequent initiation and progression of atherosclerosis [20]. Factor V, factor II, glycoprotein IIb/IIIa (GPIIb/IIIa) and plasminogen activator inhibitor type 1 (PAI-1) gene polymorphisms were also investigated. These are functional prothrombotic polymorphisms and have been implicated in the pathogenesis of MI [21-23]. The Endothelial constitutive nitric oxide synthase gene (ecNOS), G894T polymorphism was investigated as an association with the $\mathrm{T}$ allele and CVD was found in some studies [24-27]. The MTHFR C677T mutation has been studied to clarify its role in CVD. This mutation in the homozygous state is associated with raised circulating total homocysteine levels, possibly predisposing to CVD [28]. In contrast others showed no association between the MTHFR C677T mutation and CVD [29]. Matrix metalloproteinases are involved in plaque rupture. The stromelysin gene (MMP-3) exhibits a $5 \mathrm{~A} / 6 \mathrm{~A}$ polymorphism where the $5 \mathrm{~A}$ allele, is associated with susceptibility to MI [30].

Increasing evidence implicates inflammation in atherosclerosis and ischaemic heart disease (IHD) and in particular 
pro-inflammatory cytokines may promote thrombosis [31, $32,12]$. An imbalance between pro-inflammatory and antiinflammatory cytokines (i.e. a predominance of Th1 over Th2 cytokines) is thought to play a pivotal role in the development of IHD [33-37]. We chose interleukin-6 (IL-6), which has both pro- and anti-inflammatory properties and has been investigated in relation to MI. One study showed that the $\mathrm{C}$ allele of the IL- $6-174 \mathrm{G} / \mathrm{C}$ promoter polymorphism was associated with $\mathrm{MI}$ and another reported raised IL-6 levels in MI patients [38, 39]. Interleukin-13 (IL-13) is a Th2 cytokine with anti-inflammatory properties which has been implicated in the pathogenesis of asthma [40]. This cytokine has not been investigated with respect to CVD but evidence from a study in patients with asthma revealed that women but not men were at increased risk of developing IHD and this could possibly be linked to IL-13 [41]. Indeed several IL-13 polymorphisms were identified which are associated with increased levels of IgE, a predictor of asthma phenotype [42]. The functional polymorphism, IL-13 Arg $130 \mathrm{Gln}$, was associated with raised $\mathrm{IgE}$ in asthma patients and this was selected in our study [40].

\section{MATERIALS AND METHODOLOGY}

\section{Characteristics of the Cohort}

Cases $(n=77)$ and controls $(n=79)$ were unrelated individuals aged 30-65. Impaired renal function, hypothyroidism or abnormal liver functions were exclusion criteria. None of the patients recruited were on hypolipidaemic or antihypertensive drug therapy. They were all residents of the same area; a southern coast city (Larnaca, Cyprus). Cases were individuals, who had experienced a non-fatal first MI. The diagnostic criteria were 2 of the following 3 observations: an increase in creatine kinase (CK-MB) activity, an abnormal electrocardiogram and intense chest pain of long duration (WHO diagnostic criteria). The MI patients were recruited for this study 2 days after their MI. Questionnaires were completed; lipid profiles were measured within the first $18 \mathrm{~h}$ after the MI event. Blood samples were collected for DNA extraction. A resting BP measurement was taken and body mass index (BMI) was calculated. The family history was also recorded. All subjects who participated in this study gave their informed consent, and all experimental procedures were carried out in accordance with the ethical standards of the local ethics committee and with the Helsinki Declaration of 1975, as revised in 2000.

\section{DNA ANALYSES}

Genotyping for the various polymorphisms was performed as previously described [20-24, 28, 43, 44] with the exception of the IL-13 Arg130Gln polymorphism which was genotyped using a novel allelic discrimination TaqMan assay designed at the Department of Cardiovascular Genetics \& Laboratory of Forensic Genetics, Cyprus Institute of Neurology and Genetics, Nicosia, Cyprus. The assay was run on an ABI Prism 7700 Sequence Detector (Foster City, USA). The primers and probes were designed using specified software (Primer Express Version 1.5, Foster City, USA), which takes into consideration the optimum conditions for allelic discrimination. The amplicon was 78 bp long. The following PCR primers and allelic discrimination probes were designed and used for genotyping:
Forward PCR primer - AGGACCTGCTCTTACATTT AAAGAAACT,

Reverse PCR primer - TGCAAATAATGATGCTTTC GAAGT,

Allele 1 /probe 1- wild type (VIC - AGGGACGGTTC AACT, amino acid residue-arginine- $\mathrm{R}$ ),

Allele 2 /probe 2- mutated (FAM - AGGGACAGTT CAACT, amino acid residue-glutamine-Q),

The assay was validated on 20 samples of known genotype using a previously designed PCR assay with the following primers: 5'-CTT CCG TGA GGA CTG AAT GAG ACG GTC-3' (forward) and 5'-GCA AAT AAT GAT GCT TTC GAA GTT TCA GTG GA-3' (reverse), followed by NlaIV restriction digestion [40]. The procedure for TaqMan Assay performance and data analysis was carried out as instructed by the manufacturer of the ABI Prism 7700 Sequence Detector. PCR reagents (UNIVERSAL MASTER MIX) and oligonucleotides (PRIMERS \& VIC/FAM LABELED PROBES) were purchased from Applied Biosystems (Foster City, USA). In brief, the PCR conditions for the TaqMan assay were as follows: $50^{\circ} \mathrm{C}-2 \mathrm{~min} \times 1$ cycle (Temperature at which UNG is activated to degrade any PCR product that may have contaminated sample, as dUTP is used in place of dTTP for PCR in TaqMan assay), this is followed by $95^{\circ} \mathrm{C}$ 10 min (AmpliTaq Gold DNA polymerase activation) $\mathrm{x} 1$ cycle, $95^{\circ} \mathrm{C}-15$ secs (denaturation) then $60^{\circ} \mathrm{C}-1 \mathrm{~min}$ (Annealing \& Extension) x 40 cycles.

\section{STATISTICAL ANALYSES}

The statistical package SPSS V12 was used to perform the relevant statistical tests. Briefly, comparison of frequencies of genotypes and alleles were achieved using the chisquare test. Distribution of quantitative variables was determined using the Kolmogorov-Smirnov test. Mean values of quantitative variables between groups were compared using the unpaired t-test for normal data and Mann-Whitney for non-parametric data. Bivariate correlation analysis was carried out to determine any correlation between pairs of variables (Pearson's correlation). Binary logistic regression analysis was performed to determine the relative contribution of IL-13 Arg130Glu polymorphism, lower HDL-C and smoking on the dependant variable MI.

\section{RESULTS}

The frequency of diabetes in cases and controls was $16 \%$ and $19 \%$, respectively and for dyslipidaemias these values were $56 \%$ and $54 \%$, respectively. There were no significant differences when proportions were compared (chi-square analysis). Mean age between male cases and controls was not significantly different (54 \pm 8 in cases vs $52 \pm 10$ years in controls). BMI and BP were all normally distributed. No significant differences were observed between cases and controls (Table 1). Total and HDL-C were normally distributed, triglycerides were positively skewed but LDL-C was normally distributed. Mean values for total, LDL-C and HDL-C were compared between cases and controls using the unpaired t-test and for triglycerides values were compared using the Mann-Whitney test. Mean values for triglycerides, total and LDL-C did not show any significant differences. A significantly higher mean HDL-C level was observed in con- 
trols compared with cases $(45 \pm 12 \mathrm{mg} / \mathrm{dl}$ vs $40 \pm 9 \mathrm{mg} / \mathrm{dl}$; $\mathrm{P}$ $=0.001)$ (Table 1).

Table 1. Characteristics of Cases and Controls

\begin{tabular}{|c|c|c|}
\hline $\begin{array}{c}\text { Variable Mean }( \pm \mathrm{SD}) \text { or } \\
\text { Frequency }\end{array}$ & Cases $n=77$ & Controls $n=79$ \\
\hline Age & $54( \pm 8)$ & $52( \pm 10)$ \\
\hline$P$ value & \multicolumn{2}{|c|}{0.224} \\
\hline Frequency of diabetes & $16 \%$ & $19 \%$ \\
\hline$P$ value & \multicolumn{2}{|c|}{0.600} \\
\hline Frequency of dyslipidaemia & $56 \%$ & $54 \%$ \\
\hline$P$ value & \multicolumn{2}{|c|}{0.845} \\
\hline Frequency of Hypertension & $28 \%$ & $24 \%$ \\
\hline$P$ value & \multicolumn{2}{|c|}{0.611} \\
\hline Frequency of Smoking & $83 \%$ & $58 \%$ \\
\hline$P$ value & \multicolumn{2}{|c|}{0.001} \\
\hline BMI & $28.2( \pm 4)$ & $28.0( \pm 4)$ \\
\hline$P$ value & \multicolumn{2}{|c|}{0.764} \\
\hline Total Cholesterol (mg/dl) & $220( \pm 45)$ & $225( \pm 48)$ \\
\hline$P$ value & \multicolumn{2}{|c|}{0.460} \\
\hline LDL-C (mg/dl) & $139( \pm 42)$ & $142( \pm 40)$ \\
\hline$P$ value & \multicolumn{2}{|c|}{0.615} \\
\hline HDL-C (mg/dl) & $40( \pm 9)$ & $45( \pm 12)$ \\
\hline$P$ value & \multicolumn{2}{|c|}{0.001} \\
\hline Triglycerides $* *(\mathrm{mg} / \mathrm{dl})$ & $156(53-480)$ & $160(23-800)$ \\
\hline P value & \multicolumn{2}{|c|}{0.728} \\
\hline
\end{tabular}

P- value for t-test (comparison of means). BMI = body mass index; LDL-C = low density lipoprotein cholesterol; HDL-C = high density lipoprotein cholesterol; ** Median value and range in parenthesis, comparison of medians by non-parametric statistics (Mann-Whitney test).

In the case group, $83 \%$ were smokers, whereas in controls only $58 \%$ were smokers (Chi-square test $\mathrm{P}=0.001$ ). Mean HDL-C levels were significantly higher in all nonsmokers compared with all smokers $(46 \pm 13 \mathrm{mg} / \mathrm{dl}$ vs $41 \pm 9$ $\mathrm{mg} / \mathrm{dl} ; \mathrm{P}=0.013)$. A significantly higher mean value HDL-C was observed in controls who did not smoke compared with controls who did smoke $(49 \pm 14 \mathrm{mg} / \mathrm{dl}$ vs $45 \pm 10 \mathrm{mg} / \mathrm{dl}$; $\mathrm{P}$ $=0.038)$. In cases, mean HDL-C level did not differ between smokers and non-smokers $(40 \pm 9 \mathrm{mg} / \mathrm{dl}$ vs $39 \pm 9 \mathrm{mg} / \mathrm{dl} ; \mathrm{P}$ $=0.759$ ). HDL-C levels were significantly higher in controls who did not smoke compared with the corresponding MI group ( $49 \pm 14 \mathrm{mg} / \mathrm{dl}$ vs $39 \pm 9 \mathrm{mg} / \mathrm{dl} ; \mathrm{P}=0.029)$ (Table 2).

Cross tabulations between genotype and allele frequencies in cases and controls indicated that frequencies were homogeneous between the 2 groups for all polymorphic loci tested except for the IL-13 R130Q polymorphism. All genotypes were in Hardy-Weinberg equilibrium in cases and con- trols (see Table 3). For the IL-13 R130Q polymorphism, the frequency of heterozygotes (RQ) as well as homozygotes for the mutation (QQ) was significantly higher in cases compared with controls, ( 0.40 vs 0.28 for RQ and 0.09 vs 0.02 for $\mathrm{QQ} ; \mathrm{P}=0.030$ ). In addition, the difference in the mutant allele frequency was significant, $(0.29$ in cases vs 0.16 in controls; $\mathrm{P}=0.011)$. Data are shown in Table 4.

Table 2. Comparison of Mean High Density Lipoprotein Cholesterol (HDL-C) Levels (mg/dl) in Cases and Controls as A Function of Smoking Status

\begin{tabular}{|c|c|c|}
\hline & $\begin{array}{c}\text { Mean HDL-C Level } \\
( \pm \text { SD })\end{array}$ & $\begin{array}{c}\text { P-Value } \\
\text { T-Test }\end{array}$ \\
\hline $\begin{array}{c}\text { Cases } \\
\text { Smokers + Non } \\
\text { (77) smokers }\end{array}$ & $\begin{array}{c}40 \\
( \pm 9)\end{array}$ & \multirow{2}{*}{0.001} \\
\hline $\begin{array}{c}\text { Controls } \\
\text { Smokers + Non } \\
\text { (79) smokers }\end{array}$ & $\begin{array}{c}46 \\
( \pm 12)\end{array}$ & \\
\hline $\begin{array}{l}\text { Cases + Controls } \\
\text { Smokers (109) }\end{array}$ & $\begin{array}{c}41 \\
( \pm 9)\end{array}$ & \multirow{2}{*}{0.013} \\
\hline $\begin{array}{l}\text { Cases + Controls } \\
\text { Non-smokers (46) }\end{array}$ & $\begin{array}{c}46 \\
( \pm 13)\end{array}$ & \\
\hline $\begin{array}{c}\text { Controls Smokers } \\
\text { (45) }\end{array}$ & $\begin{array}{c}45 \\
( \pm 9)\end{array}$ & \multirow{2}{*}{0.038} \\
\hline $\begin{array}{c}\text { Controls } \\
\text { Non-smokers (33) }\end{array}$ & $\begin{array}{c}49 \\
( \pm 14)\end{array}$ & \\
\hline $\begin{array}{c}\text { Cases } \\
\text { Smokers (64) }\end{array}$ & $\begin{array}{c}40 \\
( \pm 9)\end{array}$ & \multirow{2}{*}{0.759} \\
\hline $\begin{array}{c}\text { Cases } \\
\text { Non-smokers (13) }\end{array}$ & $\begin{array}{c}39 \\
( \pm 9)\end{array}$ & \\
\hline $\begin{array}{c}\text { Controls } \\
\text { Non-smokers (33) }\end{array}$ & $\begin{array}{c}48 \\
( \pm 14)\end{array}$ & \multirow{2}{*}{0.029} \\
\hline $\begin{array}{c}\text { Cases } \\
\text { Non-smokers (13) }\end{array}$ & $\begin{array}{c}39 \\
( \pm 9)\end{array}$ & \\
\hline
\end{tabular}

Value in brackets indicates sample size.

The correlation matrix between all variables involved was constructed for easy comparison between correlations and for determining clusters of variables that covary. The elements (coefficients) of the matrix are used not only as measures of the degree and direction between row and column variables and the proportion of covariation but also as the guide to the logistic multiple regression statistical analysis that follows. The significant correlations are listed in Table 5. The categorical independent variable smoking and the categorical dependent variable MI were categorized as " 1 " if the answer was "yes" i.e. that individual did smoke and he had an MI; and as " 2 " if the reverse was true, i.e. that individual did not smoke and he did not have an MI. By performing the correlation analysis between these 2 variables, MI was positively correlated with a positive smoking habit $(\mathrm{r}$ $=0.270, \mathrm{P}=0.001)$. HDL-C level was positively correlated with the absence of an MI event $(r=0.263, P=0.001)$. The 
Table 3. Rare Allele Frequencies and 95\% Confidence Intervals for Gene Polymorphisms in Male Cohort

\begin{tabular}{|c|c|c|c|c|}
\hline Gene Polymorphism & Rare Allele & Relative Frequency (95\% CI) Cases & Relative Frequency (95\% CI) Controls & P-value \\
\hline \hline IL6 -174G/C & C & $0.20(0.14-0.25)$ & $0.22(0.15-0.28)$ \\
\hline IL13 R130Q & Q & $0.29(0.21-0.34)$ & $0.16(0.11-0.23)$ & 0.356 \\
\hline Stromelysin 5A/6A & 5A & $0.42(0.35-0.49)$ & $0.34(0.27-0.42)$ & 0.172 \\
\hline ACE D/I & I & $0.33(0.25-0.38)$ & $0.08(0.06-0.11)$ \\
\hline ApoE (Hinf1)* & 2 & $0.05(0.03-0.08)$ & $0.05(0.03-0.08)$ \\
\hline ApoE (Hinf1)* & 4 & $0.06(0.04-0.09)$ & $0.14(0.09-0.20)$ & 0.719 \\
\hline GPIIIa A1/A2 & A2 & $0.18(0.12-0.23)$ & $0.36(0.29-0.44)$ \\
\hline MTHFR C677T & T & $0.40(0.32-0.47)$ & $0.31(0.24-0.38)$ \\
\hline ECNOSG894T & T & $0.28(0.23-0.37)$ & $0.07(0.03-0.12)$ \\
\hline FactorV G1691A & A & $0.04(0.03-0.11)$ & $0.03(0.00-0.05)$ \\
\hline Factor II G20210A & A & $0.03(0.01-0.06)$ & 0.642 \\
\hline PAI-1 4G/5G & $4 G$ & $0.41(0.33-0.48)$ & $0.49(0.41-0.56)$ \\
\hline PON1 L55M & M & $0.40(0.32-0.48)$ & $0.46(0.38-0.53)$ \\
\hline
\end{tabular}

*ApoE Hinf1 polymorphism has three alleles 2/3/4; ApoE alleles 2 and 4 are considered rare alleles; ${ }^{+}$Difference in allele frequencies between cases and controls is statistically significant.

Table 4. IL-13 R130Q Genotype and Allele Frequencies in Case \& Control Groups (Numbers in Parenthesis Represent Relative Frequencies)

\begin{tabular}{|c|c|c|c|c|c|c|}
\hline \multirow[b]{2}{*}{ Group } & \multicolumn{5}{|c|}{ IL-13R130Q } & \multirow[b]{2}{*}{ Total N } \\
\hline & \multicolumn{3}{|c|}{ Genotypes } & \multicolumn{2}{|c|}{ Alleles } & \\
\hline Cases & $39(0.51)$ & $31(0.40)$ & $7(0.09)$ & $109(0.71)$ & $45(0.29)$ & 77 \\
\hline P-value & \multicolumn{3}{|c|}{0.030} & \multicolumn{2}{|c|}{0.011} & \\
\hline
\end{tabular}

Pearson's chi square test to compare frequency of genotypes and alleles of the; IL-13R130Q polymorphism between cases and controls.

IL-13 R130Q gene polymorphism was given the following codes in the data base: "1-RR; 2-RQ; 3-QQ". An inverse correlation was observed between the IL-13 R130Q gene polymorphism and the absence of an MI event $(r=-0.212$, P $=0.008)$. Smoking $\mathrm{w}$ as inversely correlated with HDL-C level $(\mathrm{r}=-0.201, \mathrm{P}=0.013)$ (Table 5).

Contrary to most other reports, in this particular male population, there was no correlation between ApoE genotype and any of the lipid variables (Pearson correlation analysis) nor was there any significant difference between mean lipid levels when stratified by ApoE genotype using ANOVA. However, a trend was observed which was consistent with the established effect of the ApoE genotype on lipid levels. Specifically, mean total cholesterol level was $214 \pm 40 \mathrm{mg} / \mathrm{dl}$ in individuals who had the 2/3 ApoE genotype (n=20), $223 \pm$ $47 \mathrm{mg} / \mathrm{dl}$ in individuals who had the $3 / 3$ ApoE genotype $(\mathrm{n}=115)$, and $231 \pm 55 \mathrm{mg} / \mathrm{dl}$ in individuals who had the $3 / 4$ ApoE genotype $(n=16)$. The same trend was observed for
LDL-C while triglycerides and HDL-C were more homogeneous for the 3 genotypes. Again there were no significant differences.

Variables that were significantly different between cases and controls in earlier statistical analyses were selected for binary logistic regression analysis. These were HDL-C, smoking and the IL-13 R130Q polymorphism. This analysis kept the IL-13 R130Q polymorphism, low HDL-C and smoking status as predictors of MI occurrence. For smoking, if an individual smoked the odds of an MI occurring were 2.7 times more likely than if an individual did not smoke ( $\mathrm{P}$ $=0.016$ ). For HDL-C as the concentration increased the odds of an MI occurring decreased, specifically, as the HDL-C level increases by $1 \mathrm{mg} / \mathrm{dL}$, the odds of an MI occurring decreased by $5.4 \%$. $(\mathrm{P}=0.006)$. Finally, an individual who was an IL-13 QQ homozygote was found to be 5.8 times more likely to experience an MI than one with the wild type genotype; $R R(P=0.039)$ and an individual with an $R Q$ genotype 
was 2.1 times more likely to do so $(\mathrm{P}=0.055)$. Data are shown in Table 6. If the analysis is repeated with variables: smoking, hypertension, hypercholesterolaemia, diabetes, HDL cholesterol and the IL13 R130Q SNP, the results indicate that, smoking, HDL cholesterol and the IL13 R130Q SNP are still significant risk factors for MI, whereas hypertension, hypercholesterolaemia and diabetes are not, as indicated previously in t-tests and correlation analysis.

Table 5. Pearson's Correlation Coefficients and P-Values for Bivariate Correlation Analyses

\begin{tabular}{|c|c|c|}
\hline $\begin{array}{c}\text { Pairs of Variables } \\
\text { Correlated }\end{array}$ & $\begin{array}{c}\text { Pearson Correlation } \\
\text { Coefficient }\end{array}$ & P-value \\
\hline \hline MI-SMOKING & 0.270 & 0.001 \\
\hline NO MI-HDL-C & 0.263 & 0.001 \\
\hline MI-IL-13R130Q & -0.212 & 0.008 \\
\hline SMOKING-HDL-C & -0.201 & 0.013 \\
\hline
\end{tabular}

$\mathrm{MI}=$ myocardial infarction; HDL-C = high density lipoprotein cholesterol; IL-13 = interleukin 13.

The categorical independent variable smoking and the categorical dependent variable MI were categorized as " 1 " if the answer was "yes" i.e. that individual did smoke and he had an MI; and as "2" if the reverse was true, i.e. that individual did not smoke and he did not have an MI. MI was positively correlated with a positive smoking habit. HDL-C level was positively correlated with the absence of an MI event. The IL-13 R130Q gene polymorphism was given the following codes in the data base: "1-RR; 2RQ; 3-QQ". An inverse correlation was observed between the IL-13 R130Q gene polymorphism and the absence of an MI event. Smoking was also inversely correlated with HDL-C levels.

\section{DISCUSSION}

Smoking and a comparatively low HDL-C level were associated with MI in Greek Cypriot men. The term "comparatively low" for HDL-C in our study actually refers to a value that is at the borderline of the acceptable lower limit of the normal range as defined by a pan-European survey of 8,545 dyslipidaemic patients where an HDL-C $<40 \mathrm{mg} / \mathrm{dL}$ in men is defined as low [45]. Smoking has been shown to be independently associated with vascular disease and to interact with other genetic and environmental risk factors in the cau- sation of vascular damage [46, 47]. More specifically, the pathogenic effects of smoking are attributed to its ability to increase LDL-C, plasma triglycerides and VLDL triglycerides and to simultaneously lower HDL-C [48]. Furthermore, smoking has been shown to increase oxidation and nitration of LDL-C which promote the atherogenic process $[49,50]$. Since a high percentage of the case group are smokers then it is highly likely that some of the above proatherogenic mechanisms may have contributed to the occurrence of MI. Our observations are in agreement with those of other CHD case-control studies [51, 52]. However, several other common CHD risk factors did not show an association in this study, while a novel CHD predictor emerged, the IL13 R130Q polymorphism. Due to the limited number of participants in the present pilot study, this interesting association needs to be confirmed in larger studies and the possible effect of other linked loci to the IL13 gene excluded.

Surprisingly, the established risk factor LDL-C was homogeneous between cases and controls and mean values were within normal range. Although mean LDL-C was homogeneous between the 2 groups, LDL subfraction distribution may have been heterogeneous, being more proatherogenic (LDL-3 to 7) in the case group and therefore potentially contributing to the risk of MI [53-55]. Survivors of MI may have an abundance of small, dense LDL in plasma compared with controls and further, that patients who also smoked had a more atherogenic LDL subfraction profile [56]. Small, dense LDL particles are more atherogenic than large buoyant LDL particles because they are more susceptible to form oxidized LDL and are not readily cleared [57]. Furthermore, since the immediate pre-MI, LDL-cholesterol levels were not available, we cannot rule out the possibility that prior to MI these values were higher than after the MI event. Triglycerides levels have been reported to increase small, dense LDL particles and therefore the risk of cardiovascular disease $[58,59]$. In the present study, however, a significant difference is not observed. The range in controls was greater than that of cases due to the presence of an outlier (who smoked 40-50 cigarettes per day) in the control group with $800 \mathrm{mg} / \mathrm{dL}$ triglycerides. The exclusion of this outlier from the analysis did not alter the distribution of these data or result in a significant difference in triglyceride levels

Table 6. Binary Logistic Regression Analysis

\begin{tabular}{|c|c|c|c|c|c|c|c|c|}
\hline \multirow{2}{*}{ Variable } & \multirow{2}{*}{ B } & \multirow{2}{*}{ S.E. } & \multirow{2}{*}{ Wald } & \multirow{2}{*}{ df } & \multirow{2}{*}{ Sig. } & \multirow{2}{*}{$\operatorname{Exp}(B)$} & \multicolumn{2}{|c|}{$95,0 \%$ C.I. for $\operatorname{EXP}(B)$} \\
\hline & & & & & & & Lower & Upper \\
\hline Smoker & 0.981 & 0.407 & 5.796 & 1 & 0.016 & 2.667 & 1.200 & 5.925 \\
\hline HDL-C & -0.056 & 0.020 & 7.662 & 1 & 0.006 & 0.946 & 0.909 & 0.984 \\
\hline IL-13(1-RQ) & 0.723 & 0.378 & 3.671 & 1 & 0.055 & 2.061 & 0.984 & 4.320 \\
\hline IL-13(2-QQ) & 1.758 & 0.851 & 4.263 & 1 & 0.039 & 5.799 & 1.093 & 30.754 \\
\hline Constant & 1.237 & 0.924 & 1.792 & 1 & 0.181 & 3.444 & & \\
\hline
\end{tabular}

HDL-C = high density lipoprotein cholesterol; IL-13 = interleukin 13 .

Variables which are significant contributors to the occurrence of an MI in a sample of Cypriot men (smoking, relatively low HDL-C and the IL-13 R130Q mutation). 
between the 2 groups. Since there is no difference between groups in triglyceride levels, the hypothesized difference in the LDL subfraction profile in our 2 groups may be mediated by other factors such as smoking [58-60]. In contrast to the above hypotheses, no correlation was observed between smoking and triglyceride level in this study, or between MI occurrence and triglyceride level. It is therefore more likely that any effects of the hypothetical proatherogenic small dense LDL profile preponderance in cases compared to controls is caused largely by smoking.

Future studies will need to include LDL subfractions. Such testing has in fact been suggested by the (NCEP ATP III) National Cholesterol Education Program Adult Treatment Panel in addition to the conventional lipid profile [61]. In addition, the ApoE genotype did not seem to have a significant effect on total cholesterol level. The Mediterranean diet may account for the relatively normal mean cholesterol level in the study population as a whole.

A significantly higher mean HDL-C level was observed in controls compared with cases. In cases, the mean HDL-C level was low irrespective of smoking status suggesting that other factors may be involved in lowering this protective factor. Other genetic factors or dietary habits/deficiency may be the cause of the significantly lower HDL-C in cases compared with controls. HDL-C levels were significantly higher in controls that did not smoke compared with the corresponding MI group (48 mg/dl vs $39 \mathrm{mg} / \mathrm{dl} \mathrm{P}=0.029)$. The latter comparison highlights the effect of low HDL-C per se on the occurrence of an MI. Our findings regarding HDL-C suggest that the currently accepted lower value of $(40 \mathrm{mg} / \mathrm{dl})$ as satisfactory should be raised (Adult Treatment Panel IIIwww.nhlbi.nih.gov/guidelines/cholesterol, 2005). However, such a suggestion is limited by the small numbers in our study and it may only apply to a Mediterranean population known to have a very high smoking rate. Several intervention studies, such as the Veterans Affairs High-Density Lipoprotein Cholesterol Intervention Trial (VA-HIT) and HDL-Atherosclerosis Treatment Study (HATS), provided evidence that a rise in HDL-C significantly reduces cardiovascular risk [6-8, 62-64]. The protective effect of HDL arises from multiple actions including reverse cholesterol transport [63, 65, 66]. Furthermore, HDL enhances nitric oxide synthesis and improves endothelium-dependent relaxation [67].

Many studies focused on lipid lowering as a way of reducing the risk for CVD. However, with recent evidence for the involvement of inflammation in atherosclerosis, it is relevant that statins exert anti-inflammatory effects. This effect together with lipid lowering and other actions may contribute to the overall clinical benefit observed in trials [32, 68, 69].

The association of the IL-13 R130Q polymorphism with MI in Greek Cypriot men in the present pilot study is quite novel and provides the impetus for the design of future experiments using a larger cohort size. The investigation of this variant at different stages of acute coronary syndromes (ACS) may also be an important study, as the variant may be of predictive value for MI and may have important implications for preventive and therapeutic regimens. In light of the many functions of IL-13 and the pathways in which it is in- volved, some hypotheses may be proposed regarding this novel association. Wild type IL-13 suppresses macrophage production of proinflammatory mediators, regulates extracellular matrix, inhibits tissue factor expression induced by bacterial lipopolysaccharides, reduces the pyrogenic effects of IL-1 or TNF thus protecting endothelial and monocyte surfaces against inflammatory mediator-induced procoagulant changes [70-72]. It is possible, therefore that this variant may, favour coagulation, thrombus formation and coronary artery occlusion or it may activate matrix metalloproteinases and consequently extracellular matrix degradation leading to coronary artery plaque destabilization, rupture and ultimately MI. Furthermore, a comparison of recombinant wild type IL13 and IL-13 R130Q activity in primary monocytes has indicated that IL-13 R130Q is more active in inducing the main steps in the IL-13-dependent signaling pathway, including IgE synthesis [73]. In relation to this, an earlier study reported that among other raised inflammatory markers encountered in MI patients, raised IgE is also observed. It is further suggested that this may participate in plaque-rupture and ultimately in MI events [74]. An, alternative hypothesis is that these studies also provide a possible mechanism which may explain the association of the IL-13 R130Q mutation, (possibly by raising $\mathrm{IgE}$ ) and occurrence of MI events in our pilot study. In future studies we will investigate whether MI patients will show a concurrent association with the IL13 R130Q mutation, raised IL-13 activity as well as raised IgE. Additionally, the IL-13 R130Q variant has been linked to eosinophilia, and the latter has been shown to predict cardiovascular and cerebrovascular mortality possibly through endothelial inflammation and ultimately atherosclerosis. The mechanisms suggested include the secretion of 2 proteins (cationic protein and major basic protein) which activate mast cells to release histamine which causes coronary artery spasm and arrhythmias. Secondly, arachidonate 15-lipoxygenase which is expressed at high levels in eosinophils may be involved in oxidative modification of LDL cholesterol and therefore in atherosclerosis, a major cause for MI [75, 76]. In conclusion, the important findings of this first pilot study concerning Greek Cypriot men and MI, point out that larger scale studies should be encouraged to confirm and study further the role of the putative novel genetic risk factor IL-13 R130Q and lipid levels in MI in Cyprus.

\section{REFERENCES}

[1] Shepherd J, Cobbe SM, Ford I, et al. Prevention of coronary heart disease with pravastatin in men with hypercholesterolemia. West of Scotland Coronary Prevention Study Group. N Engl J Med 1995; 333: 1301-7.

[2] Quist-Paulsen P, Gallefoss F. Randomised controlled trial of smoking cessation intervention after admission for coronary heart disease. BMJ 2003; 327(7426): 1254-7.

[3] Yusuf S. Hawken S. Ounpuu S, et al. INTERHEART Study Investigators. Effect of potentially modifiable risk factors associated with myocardial infarction in 52 countries (the INTERHEART study): case-control study. Lancet 2004; 364: 937-952.

[4] Rosengren A, Hawken S, Ounpuu S, et al. INTERHEART investigators. Association of psychosocial risk factors with risk of acute myocardial infarction in 11119 cases and 13648 controls from 52 countries (the INTERHEART study): case-control study. Lancet 2004; 364: 912-914.

[5] Amowitz LL, Ridker PM, Rifai N, et al. High prevalence of metabolic syndrome among young women with nonfatal myocardial infarction. J Womens Health (Larchmt) 2004; 13: 165-75; discussion 175 . 
[6] Athyros VG, Ganotakis ES, Bathianaki M, et al. MetS-Greece Collaborative Group. Awareness, treatment and control of the metabolic syndrome and its components: a multicentre Greek study. Hellenic J Cardiol 2005; 46: 380-6.

[7] Robins SJ. Targeting low high-density lipoprotein cholesterol for therapy: lessons from the Veterans Affairs High-density Lipoprotein Intervention Trial. Am J Cardiol 2001; 88(12A):19N-23N.

[8] Robins SJ, Collins D, Wittes JT, et al. Relation of gemfibrozil treatment and lipid levels with major coronary events: VA-HIT: a randomized controlled trial. JAMA 2001; 285: 1585-91.

[9] Jukema JW, Bruschke AV, van Boven AJ, et al. Effects of lipid lowering by pravastatin on progression and regression of coronary artery disease in symptomatic men with normal to moderately elevated serum cholesterol levels. The Regression Growth Evaluation Statin Study (REGRESS). Circulation 1995; 91: 2528-2540.

[10] Farnier M, Davignon J. Current and future treatment of hyperlipidemia: the role of statins. Am J Cardiol 1998; 82(4B): 3J-10J.

[11] Nissen SE, Tuzcu EM, Schoenhagen P, et al. Effect of intensive compared with moderate lipid-lowering therapy on progression of coronary atherosclerosis: a randomized controlled trial. JAMA 2004; 291: 1071-1080.

[12] Libby P. Inflammation in atherosclerosis. Nature 2002; 420: 868874 .

[13] McCarthy JJ, Parker A, Salem R, et al. Large scale association for identification of genes underlying premature coronary heart disease: cumulative perspective from analysis of 111 candidate genes. J Med Genet 2004; 41: 334-341.

[14] Pretorius M, Rosenbaum D, Vaugham DE, et al. Angiotensinconverting enzyme inhibition increases human vascular tissue-type plasminogen activator release through endogenous bradykinin. Circulation 2003; 107: 579-585.

[15] Marques-Vidal P, Bongard V, Ruidavets JB, et al. Effect of apolipoprotein $\mathrm{E}$ alleles and angiotensin-converting enzyme insertion/deletion polymorphisms on lipid and lipoprotein markers in middle-aged men and in patients with stable angina pectoris or healed myocardial infarction. Am J Cardiol 2003; 92: 1102-1105.

[16] Malygina NA, Kostomarova IV, Melent'ev AS, et al. ACE I/D polmorphism and hereditary predisposition to myocardial infarction. Klin Med (Mosk) 2002; 80: 25-29.

[17] Kolovou G, Yiannakouris N, Hatzivassiliou M, et al. Association of apolipoprotein E polymorphism with myocardial infarction in Greek patients with coronary artery disease. Curr Med Res Opin 2002; 18: 118-24.

[18] Kolovou GD, Daskalova DCH, Hatzivassiliou M, et al. The epsilon 2 and 4 alleles of apolipoprotein $E$ and ischemic vascular events in the Greek population-implications for the interpretation of similar studies. Angiology 2003; 54: 51-8.

[19] Kolovou GD, Anagnostopoulou KK, Salpea KD, et al. Apolipoprotein $\mathrm{E}$ genotype in matched men and women with coronary heart disease. Ann Clin Lab Sci 2005; 35: 391-6.

[20] Mackness B, Durrington PN, Mackness MI. The paraoxonase gene family and coronary heart disease. Curr Opin Lipidol 2002; 13 : 357-362.

[21] Arruda VR, Siquiera LH, Chiaparini LC, et al. Prevalence of the prothrombin gene variant $20210 \mathrm{G} / \mathrm{A}$ among patients with myocardial infarction. Cardiovasc Res 1998; 37: 42-45.

[22] Rosendaal FR, Siscovick DS, Schwartz SM, et al. Factor V Leiden (resistance to activated protein $\mathrm{C}$ ) increases the risk of myocardial infarction in young women. Blood 1997; 89: 2817.

[23] Ossei-Gerning N, Mansfield MW, Stickland MH. Plasminogen activator inhibito-1 promoter $4 \mathrm{G} / 5 \mathrm{G}$ genotype and plasma levels in relation to a history of myocardial infarction in patients characterized by coronary angiography. Arterioscler Thromb Vasc Biol 1997; 17: 33-37.

[24] Shimasaki Y, Yasue H, Yoshimura M, et al. Association of the missense Glu298Asp variant of the endothelial nitric oxide synthase gene with myocardial infarction. J Am Coll Cardiol 1998; 31 : 1506-10.

[25] Wei D, Shan J, Chen Z, et al. The G894T mutation of the endothelial nitric oxide synthase gene is associated with coronary atherosclerotic heart disease in Chinese. Zhonghua Yi Xue Yi Chuan Xue Za Zhi 2002; 19: 471-4.

[26] Via M, Lopez-Alomer A, Valveny N, et al. Lack of association between eNOS gene polymorphisms and ischemic heart disease in the Spanish population. Am J Med Genet 2003; 116: 243-248.
[27] Paradossi U, Ciofini E, Clerio A, et al. Endothelial function and carotid intima-media thickness in young healthy subjects among endothelial nitric oxide synthase Glu298 $\rightarrow$ Asp and T-786 $\rightarrow$ C polymorphisms. Stroke 2004; 35: 1305-1309.

[28] Wu AH, Tsongalis GJ. Correlation of polymorphisms to coagulation and biochemical risk factors for cardiovascular diseases. Am J Cardiol 2001; 87: 1361-6.

[29] Rothenbacher D, Fischer HG, Hoffmann MM, et al. Homocysteine and methylenetetrahydrofolate reductase genotype: association with risk of coronary heart disease and relation to inflammatory, hemostatic and lipid parameters. Atherosclerosis 2002; 162: 193-200.

[30] Nojiri T, Morita H, Imai Y, et al. Genetic variations of matrix metalloproteinase- 1 and -3 promoter regions and their associations with susceptibility to myocardial infarction in Japanese. Int J Cardiol 2003; 92: 181-186.

[31] Yeh ET, Anderson HV, Pasceri V, et al. C-reactive protein linking inflammation to cardiovascular complications. Circulation 2001; 104: 974-975.

[32] Plenge JK, Hernandez TL, Weil KM, et al. Simvastatin lowers Creactive protein within 14 days: an effect independent of lowdensity lipoprotein cholesterol reduction. Circulation 2002; 106: 1447-1452.

[33] Zhou RH, Shi Q, Gao HQ, et al. Changes in serum interleukin-8 and interleukin-12 levels in patients with ischaemic heart disease in a Chinese population. J Atherosclerosis Thromb 2001; 8: 30-32.

[34] Smith DA, Irving SD, Sheldon J, et al. Serum levels of the antiinflammatory cytokine interleukin-10 are decreased in patients with unstable angina. Circulation 2001; 104: 746-749.

[35] Blankenberg S, Tiret L, Bickel C, et al. Interleukin -18 is a strong predictor of cardiovascular death in stable and unstable angina. Circulation 2002; 106: 24-30.

[36] Heeschen C, Dimmeler S, Hamm CW, et al. Serum level of the anti-inflammatory cytokine interleukin-10 is an important prognostic determinant in patients with acute coronary syndromes. Circulation 2003; 107: 2109-2114.

[37] Yamashita H, Shimada K, Seki E, et al. Concentrations of interleukins. Interferon and C-reactive protein in stable and unstable angina pectoris. Am J Cardiol 2003; 91: 133-136.

[38] Georges JL, Loukaci V, Poirier O, et al. Interleukin -6 gene polymorphisms and susceptibility to myocardial infarction: the ECTIM study. Etude Cas-Temoin de l'Infarctus du Myocarde. J Mol Med 2001; 79: 300-305.

[39] Salobir B, Sabovic M. Possible vascular-bed-specific role of interleukin-6 in young women with a history of myocardial infarction lacunar cerebral infarction and deep vein thrombosis. Cytokine 2004; 25: 265-272.

[40] Graves PE, Kabesch SM, Holberg CJ, et al. A cluster of seven tightly linked polymorphisms in the IL-13 gene is associated with total serum IgE levels in three populations of white children. J Allergy Clin Immunol 2000; 105: 506-513.

[41] Iribarren C, Tolstykh IV, Eisner MD. Are patients with asthma at increased risk of coronary heart disease. Int J Epidemiol 2004; 33: 743-748.

[42] Hoffjan S, Ostrovnaja I, Nicolae D, et al. Genetic variation in immunoregulatory pathways and atopic phenotypes in infancy. J Allergy Clin Immunol 2004; 113: 511-8.

[43] Hixson JE, Vernier DT. Restriction isotyping of human apo-E by gene amplification and cleavage with HhaI. J Lipid Res 1990; 31: 545-548.

[44] Rigat B, Hubert C, Alhenc-Gelas F, et al. An insertion/deletion polymorphism in the angiotensin 1-converting enzyme accounting for half the variance of serum enzyme levels. J Clin Invest 1990; 86: 1343-1346.

[45] Bruckert E, Baccara-Dinet M, McCoy F, et al. High prevalence of low HDL-cholesterol in a pan-European survey of 8545 dyslipidaemic patients. Curr Med Res Opin 2005; 21: 1927-1934.

[46] Malin R, Loimaala A, Nenonen A, et al. Relationship between high-density lipoprotein paraoxonase gene M/L55 polymorphism and carotid atherosclerosis differs in smoking and nonsmoking men. Metabolism 2001; 50: 1095-101.

[47] Risley P, Jerrard-Dunne P, Sitzer M, Buehler A, von Kegler S, Markus HS. Carotid Atherosclerosis Progression Study. Promoter polymorphism in the endotoxin receptor (CD14) is associated with increased carotid atherosclerosis only in smokers: the Carotid Atherosclerosis Progression Study (CAPS). Stroke 2003; 34(3): 600-4. 
[48] Freeman DJ, Griffin BA, Murray E, et al. Smoking and plasma lipoproteins in man: effects on low density lipoprotein cholesterol levels and high density lipoprotein subfraction distribution. Eur $\mathbf{J}$ Clin Invest 1993; 23: 630-40.

[49] Tsiara S, Elisaf M, Mikhailidis DP. Early vascular benefits of statin therapy. Curr Med Res Opin 2003; 19: 540 - 556.

[50] Yamaguchi Y, Haginaka J, Morimoto S, et al. Facilitated nitration and oxidation of LDL in cigarette smokers. Eur J Clin Invest 2005; 35: 186-93.

[51] Castelli WP, Anderson K, Wilson PW, et al. Lipids and risk of coronary heart disease. The Framingham Study. Ann Epidemiol 1992; 2: 23-28.

[52] Gotto AM Jr, Brinton EA. Assessing low levels of high-density lipoprotein cholesterol as a risk factor in coronary heart disease: a working group report and update. J Am Coll Cardiol 2004; 43: 71724.

[53] Freedman DS, Otvos JD, Jeyarajah EJ, et al. Relation of lipoprotein subclasses as measured by proton nuclear magnetic resonance spectroscopy to coronary artery disease. Arterioscler Thromb Vasc Biol 1998; 18: 1046-53.

[54] Bernies K, Jeanneret C, Muser J, et al. Low-density lipoprotein size and subclasses are markers of clinically apparent and non-apparent atherosclerosis in type 2 diabetes. Metabolism 2005; 54: 227-234.

[55] Koba S, Hirano T, Yoshino G, et al. Remarkably high prevalence of small dense low-density lipoprotein in Japanese men with coronary artery disease, irrespective of the presence of diabetes. Atherosclerosis 2002; 160: 249-56.

[56] Theodoraki TG, Tsoukatos DC, Karabina SA, et al. LDL subfractions in patients with myocardial infarction: effect of smoking and beta-blocker treatment. Ann Clin Biochem 2000; 37(Pt 3): 313-8.

[57] Nesto RW. Beyond low-density lipoprotein: addressing the atherogenic lipid triad in type 2 diabetes mellitus and the metabolic syndrome. Am J Cardiovasc Drugs 2005; 5: 379-87.

[58] Rizzo M, Barbagallo CM, Severino M, et al. Low-densitylipoprotein peak particle size in a Mediterranean population. Eur J Clin Invest 2003; 33: 126-33.

[59] Rizzo M, Berneis K, Corrado E, Novo S. The significance of lowdensity-lipoproteins size in vascular diseases. Int Angiol 2006; 25(1): 4-9.

[60] Griffin BA, Freeman DJ, Tait GW, et al. Role of plasma triglyceride in the regulation of plasma low density lipoprotein (LDL) subfractions: relative contribution of small, dense LDL to coronary heart disease risk. Atherosclerosis 1994; 106: 241-53.

[61] Gazi I, Tsimihodimos V, Filippatos T, Bairaktari E, Tselepis AD, Elisaf M. Concentration and relative distribution of low-density lipoprotein subfractions in patients with metabolic syndrome defined according to the National Cholesterol Education Program criteria. Metabolism 2006; 55: 885-91.
[62] Sprecher DL. Raising high-density lipoprotein cholesterol with niacin and fibrates: a comparative review. Am J Cardiol 2000; 86(12A): 46L-50L

[63] Young CE, Karas RH, Kuvin JT. High-density lipoprotein cholesterol and coronary heart disease. Cardiol Rev 2004; 12: 107-19.

[64] Otvos JD, Collins D, Freedman DS, et al. Low-density lipoprotein and high-density lipoprotein particle subclasses predict coronary events and are favorably changed by gemfibrozil therapy in the Veterans Affairs High-Density Lipoprotein Intervention Trial. Circulation 2006; 113: 1556-63.

[65] Spieker LE, Ruschitzka F, Badimon JJ, et al. Shear stressdependent platelet function after LDL cholesterol apheresis. Thromb Res 2004; 113: 395-398.

[66] Perez-Mendez O. High density lipoproteins (HDL). A therapeutic objective in the atherosclerosis prevention? Arch Cardiol Mex 2004; 74: 53-67.

[67] Nofer JR, van der Giet M, Tolle M, et al. HDL induces NOdependent vasorelaxation via the lysophospholipid receptor S1P3. J Clin Invest 2004; 113: 569-581.

[68] Tsiara S, Elisaf M, Mikhailidis DP. Influence of smoking on predictors of vascular disease. Angiology 2003; 54: 507-530.

[69] Ray KK, Cannon CP, Cairns R, et al. PROVE IT-TIMI 22 Trial. Relationship between uncontrolled risk factors and C-reactive protein levels in patients receiving standard or intensive statin therapy for acute coronary syndromes in the PROVE IT-TIMI 22 trial. J Am Coll Cardiol 2005; 46: 1417-24.

[70] Doherty TM, Kastelein R, Menon S, et al. Modulation of murine macrophage function by IL-13. J Immunol 1993; 151: 7151-7160.

[71] Herbert JM, Savi P, Laplace MC, et al. IL-4 and IL-13 exhibit comparable abilities to reduce pyrogen-induced expression of procoagulant activity in endotheVlial cells and monocytes. FEBS Lett 1993; 328: 268-270.

[72] Vaillant B, Chiaramonte MG, Cheever AW, et al. Regulation of hepatic fibrosis and extracellular matrix genes by the Th response: new insight into the role of tissue inhibitors of matrix metalloproteinases. J Immunol 2001; 167: 7017-26.

[73] Vladich FD, Brazille SM, Stern D, et al. IL-13R130Q, a common variant associated with allergy and asthma, enhances effector mechanisms essential for human allergic inflammation. J Clin Invest 2005; 115 (3): 747-754.

[74] Erdogan O, Gul C, Altun A, et al. Increased Immunoglobin E response in acute coronary syndromes. Angiology 2003; 54(1): 73-79.

[75] Zhu Z, Homer RJ, Wang Z, et al. Pulmonary expression of interleukin-13 causes inflammation, mucus hypersecretion, subepithelial fibrosis, physiologic abnormalities, and eotaxin production. J Clin Invest 1999; 103(6): 779-788.

[76] Hospers J, Rijcken B, Schouten J, Postma DS, Weiss ST. Eosinophilia and positive skin tests predict cardiovascular mortality in a general population sample followed for 30 years. Am J Epidemiol 1999; 150 (5): 482-490.

(C) Xenophontos et al.; Licensee Bentham Open.

This is an open access article distributed under the terms of the Creative Commons Attribution License (http://creativecommons.org/licenses/by/2.5/), which permits unrestrictive use, distribution, and reproduction in any medium, provided the original work is properly cited. 